\title{
Electronic spectral studies and thermodynamic parameters of 5-Fluoro -1, 3- Dimethyl Uracil
}

\author{
Lalit Kumar $^{1}$, Jyoti Chaudhary ${ }^{2}$ \\ 1. Meerut College, Meerut $(U, P)$ \\ 2. Shaheed Mangal Pandey Govt.Girls (P.G) College, Meerut
}

\begin{abstract}
The ultraviolet absorption spectra of this molecules have been recorded in various solvents. Thermodynamic parameters such as total energy, zero-point energy, rotational constants dipole moment, thermal energy, specific heat and entropy of 5-Fluoro-1, 3-Dimethyl Uracil are calculated. The plots of thermodynamic parameters have been given in following paper.
\end{abstract}

Keywords: Ultraviolet absorption, thermodynamic parameters, 5-1,3FDMU etc.

\section{Introduction}

Uracil molecules are widely distributed in living organisms and find applications in biochemistry and clinical chemistry [1-3]. Recent spectroscopic studies of uracil and its derivatives have been motivated because of their biological and pharmaceutical importance. Uracil and its derivatives serves as allosteric regular and coenzymes for reactions in the human body and in plants. Some of its derivatives used as an anticancer drug (These drug inhibits RNA replication enzymes, thereby diminating RNA synthesis and stopping the growth of cancerous cell ).Some of them are the basic constituents of DNA and RNA and play an important role in constitution properties of nucleic acids[4-5]. Recently computational methods based on density functional theory are becoming widely used. In the past two decades, ab initio quantum mechanical calculations of molecular structure and force field have contributed much to understanding of the vibrational spectra of organic compounds [6-9].

\section{Experimental Details:}

The thermodynamic parameters viz enthalpy function $\left[\mathrm{H}^{0}-\mathrm{E}_{0}^{0}\right] / T$, heat capacity $\mathrm{C}_{\mathrm{P}}^{0}$, free energy $\left[\mathrm{F}^{0}-\mathrm{E}_{0}^{0}\right] / \mathrm{T}$ and entropy $\mathrm{S}^{0}$ at different temperatures are calculating from rigid rotator-harmonic oscillator approximation. The absorption spectrum of the compound was recorded in the range $200-400 \mathrm{~nm}$ with the Perkin Elmer Lambda 25 UV/VIS Spectrometer. were carried out at University scientific and instrumentation centre (USIC), Delhi University .

\subsection{Uv-Vis Absorption Spectra}

\section{Result And Discussion}

In the visible and u.v. region the wavelength intensity and general appearance of the electronic bands, along with the effect of environmental conditions such as solvent and $\mathrm{pH}$ of the solutions are the important features for the characterization of compounds. The absorption spectra of pyrimidine bases show three or four absorption bands between $180-300 \mathrm{~nm}$. In addition to the long wavelength $\mathrm{n}-\pi^{*}$ transition, these bands appear in many pyrimidine bases and the presumably $\pi-\pi^{*}$ transitions. The corralations indicate that the spectrum of each base is simply related to the spectrum of pyrimidine whose electronic states are derived from those of benzene. Thus benzene serves as the parent absorbing chromophore for all the pyrimidine bases[ 10-11]. Hence in view of the above discussion, the investigation has been undertaken to study the spectrum of 5-Fluoro-1,3-Dimethyl Uracil. The electronic spectra of this compound have been recorded in various polar solvents and their effect on electronic spectra have been discussed. In the present study, the UV spectra of 5-Fluoro-1, 3-Dimethyl Uracil were recorded in different solvents viz ethanol, methanol and water. The absorption spectrum of the molecule 5-Fluoro-1, 3-Dimethyl Uracil in the range $200-400 \mathrm{~nm}$ are given in Fig. 1.1. The observed bands of these molecules in ethanol, methanol and water are shown in Table 1.1. West [12] has suggested that changing of the solvent, effect the positions of bands in the electronic spectra which may be used to identify the bands as $\mathrm{n}-\pi^{*}, \pi-\pi^{*}$ or $\mathrm{n}-\sigma^{*}$. Generally the solvent used in recording these spectrum are non polar one (like hexane) or polar solvents (like ethanol, methanol and water). The band will be called blue shifted or red shifted according as the band shifts towards shorter wavelength or longer wavelength. On changing the solvent from hexane to water, the $n-\pi^{*}$ transitions are attributed to blue shift bands, while $\pi-\pi^{*}$ and $\mathrm{n}-\sigma^{*}$ transitions are attributed to red shift band. During the present investigation, the $\mathrm{n}-\pi^{*}$ 
are blue shifted in the title compound, with increasing polarity of the solvents i.e. (ethanol $\rightarrow$ methanol $\rightarrow$ water) as shown in the table 1.1 and in Fig. 1.1.

Table 1.1 Solvent Effect on Electronic Transitions of 5 -Fluoro-1,3-Dimethyl Uracil (All values are in $\mathbf{n m}$ )

\begin{tabular}{|c|c|c|c|c|c|}
\hline Solvent & Refractive Index & Dielectric constant & $\mathbf{n}-\boldsymbol{\pi}^{*}$ & $\boldsymbol{\pi}-\boldsymbol{\pi}^{*}$ & $\mathbf{n}-\boldsymbol{\sigma}^{*}$ \\
\hline Ethanol & 1.3773 & 25.0 & 271 & 262 \\
\hline Methanol & 1.3362 & 32.0 & 272 & - \\
\hline Water & 1.3380 & 80.5 & 226 & 206.5 \\
\hline
\end{tabular}

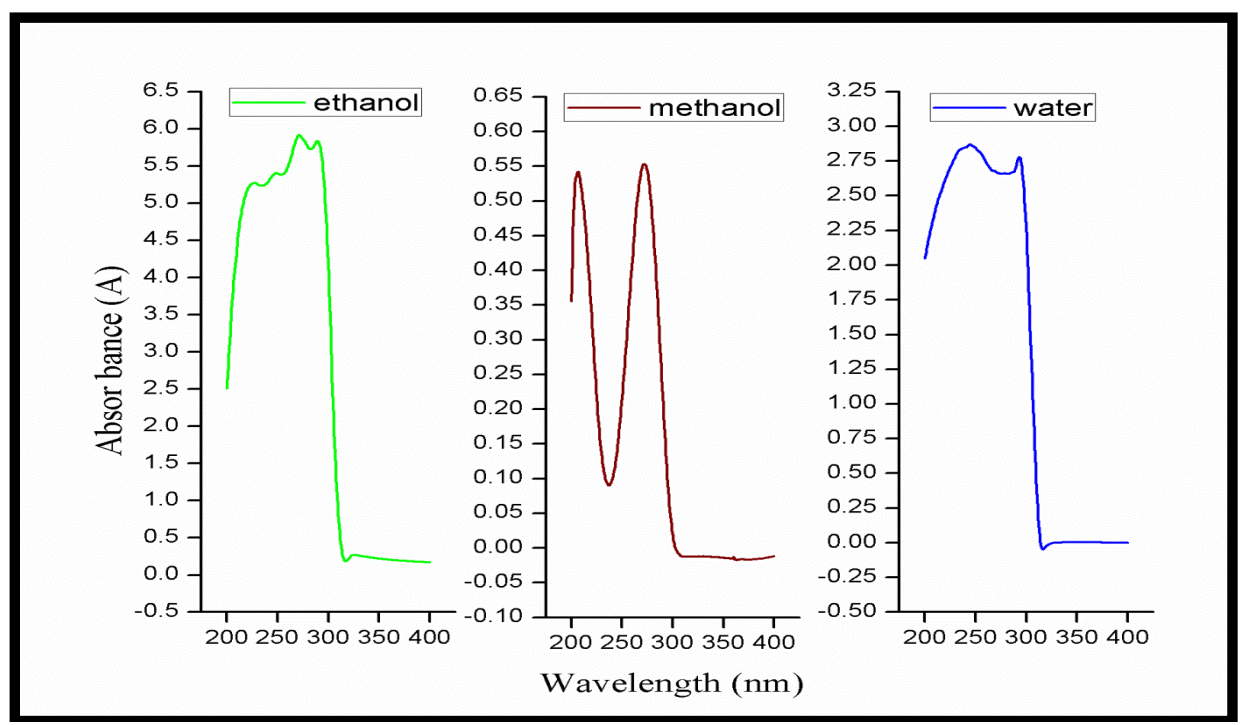

Fig. 1.1: Near ultraviolet absorption spectra of 5-fluoro-1,3-dimethyl uracil in ethanol, methanol and water

\subsection{Thermodynamic Parameters}

The partition function and the statistical theory of enthalpy function $\left[\mathrm{H}^{0}-\mathrm{E}_{0}^{0}\right] / T$, heat capacity $\mathrm{C}_{\mathrm{P}}^{0}$, free energy $\left[\mathrm{F}^{0}-\mathrm{E}_{0}^{0}\right] / \mathrm{T}$ and entropy $\mathrm{S}^{0}$ have been discussed bfire optimization. To calculate the thermodynamic parameters one requires the principal moments of inertia, molecular weight, temperature and the vibrational fundamentals. The thermodynamic functions of 5-Fluoro-1,3-Dimethyl Uracil have been calculated with the help of computer program at different temperatures between 200-1500 K using the experimental fundamental frequencies assuming rigid rotor-harmonic oscillator approximation [13]. The thermodynamic parameters viz enthalpy function $\left[\mathrm{H}^{0}-\mathrm{E}_{0}^{0}\right] / T$, heat capacity $\mathrm{C}_{\mathrm{P}}^{0}$, free energy $\left[\mathrm{F}^{0}-\mathrm{E}_{0}^{0}\right] / \mathrm{T}$ and entropy $\mathrm{S}^{0}$ at different temperatures are given in Tables 1.2. The plots of thermodynamic parameters have been given in Fig. 1,2 and it was found that the thermodynamic functions rise more rapidly in the low temperature range and less rapidly in the high temperature range. At low emperatures only translational parts of motion gives its contribution but as temperature increases rotational and vibrational motions are excited [14]. Beyond a certain value of temperature (nearly at $1000 \mathrm{~K}$ ) there is no further increase in molecular motion and therefore heat capacity becomes almost constant.

Table 1.2: Thermodynamic Functions of 5-Fluoro-1,3-Dimethyl Uracil (in Cal. /Mol-K).

\begin{tabular}{|c|c|c|c|c|}
\hline $\begin{array}{c}\text { Temperature } \\
\text { K }\end{array}$ & Enthalpy $\quad\left(\mathbf{H}^{0}-\mathbf{E}_{0}{ }^{0}\right) / \mathrm{T}$ & Heat Capacity $C_{p}{ }^{0}$ & $\begin{array}{r}\text { Free energy } \\
\left.\mathbf{E}_{0}^{0}\right) / \mathbf{T}\end{array}$ & $\begin{array}{ll}\text { Entropy } & S^{0}\end{array}$ \\
\hline 200 & 9.61 & 14.20 & 103.85 & 113.46 \\
\hline 300 & 12.29 & 21.13 & 108.24 & 120.53 \\
\hline 400 & 15.36 & 27.99 & 112.19 & 127.55 \\
\hline 500 & 18.56 & 34.62 & 115.96 & 134.51 \\
\hline 600 & 21.76 & 40.92 & 119.63 & 141.39 \\
\hline 700 & 24.93 & 46.78 & 123.22 & 148.14 \\
\hline 800 & 27.99 & 52.12 & 126.75 & 154.74 \\
\hline 900 & 30.95 & 56.93 & 130.22 & 161.17 \\
\hline 1000 & 33.76 & 61.22 & 133.63 & 167.39 \\
\hline 1100 & 36.44 & 65.02 & 136.97 & 173.41 \\
\hline 1200 & 38.96 & 68.38 & 140.25 & 179.21 \\
\hline 1300 & 41.34 & 71.34 & 143.46 & 184.80 \\
\hline 1400 & 43.58 & 73.95 & 146.61 & 190.19 \\
\hline
\end{tabular}




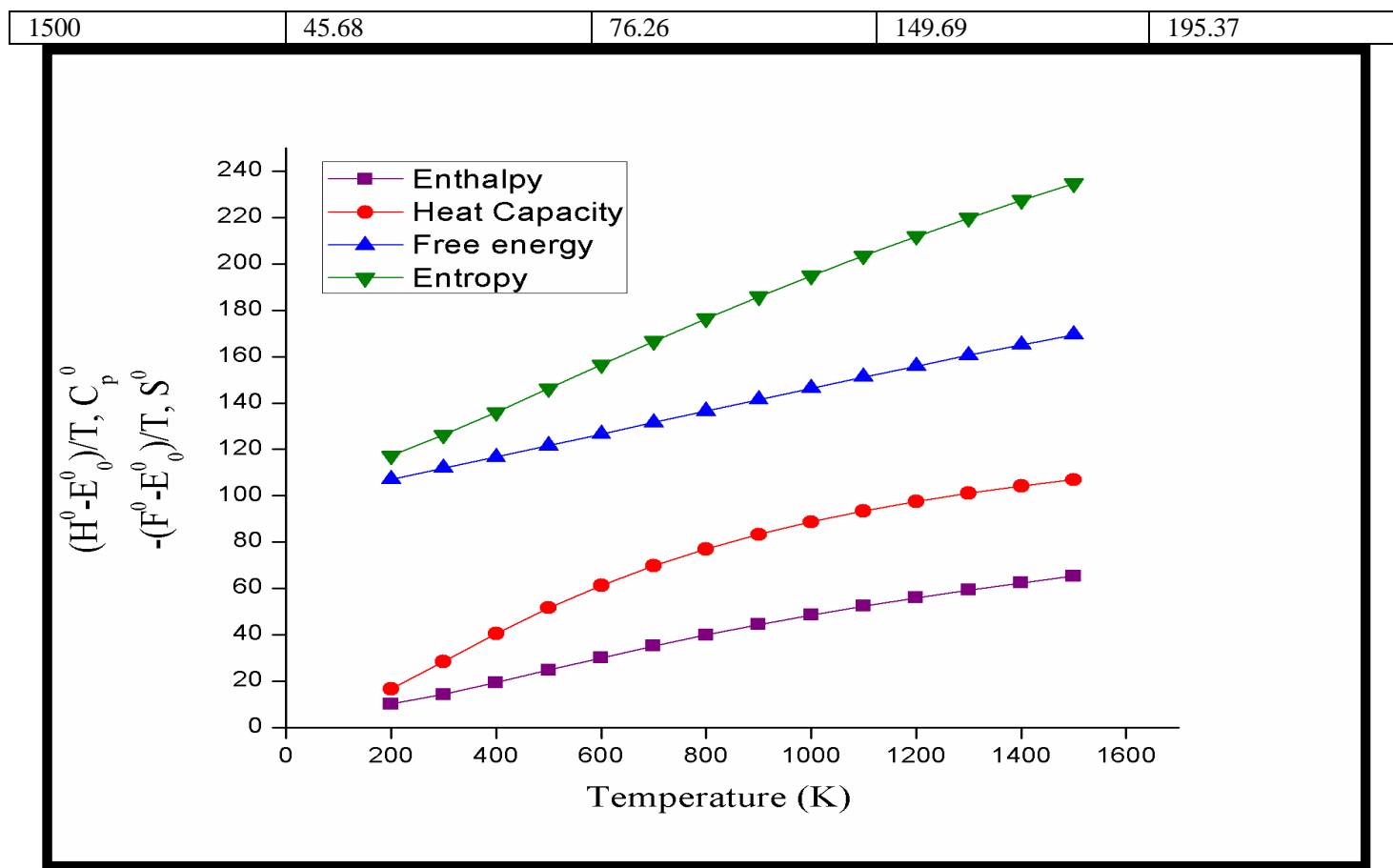

Fig. 1.2: Temperature V/s enthalpy, heat capacity, free energy and entropy of 5-fluoro 1, 3-dimethyl uracil

\section{Conclusion}

The absorption spectrum, thermodynamic parameters viz enthalpy function $\left[\mathrm{H}^{0}-\mathrm{E}_{0}^{0}\right] / \mathrm{T}$, heat capacity $\mathrm{C}_{\mathrm{P}}{ }^{0}$, free energy $\left[\mathrm{F}^{0}-\mathrm{E}_{0}^{0}\right] / \mathrm{T}$ and entropy $\mathrm{S}^{0}$ at different temperatures are in good agreement with standard results.

\section{Acknowledgement}

The author are thankful to USIC, Delhi University for recording the absorption spectra.

1. J. G. Contreras, V. Seguel, Spectrochim. Acta A 48, 525 (1992).

[2] A. Pullman, Pullman, Adv, Hetrocycl. Chem. 13, 77(1971).

[3] M Arivazhagan \& V Krishnakumar Indian J Pure \& Applied Phys, 41(2003) 341.

[4] RA Cox; Quart. Rev.; 1968; 22; 499

[5] R.E. Handshumacher and A.D. Welch, "The nucleic acids" (Academic Press, New York ) 1960.

[6] R.C. Lord and J.G. Thomas Jr., Spectrochim Acta, 23(A), 2551 (1967).

[7] V.K. Rastogi, Y.C. Sharma and S.N. Sharma, Eds. R.E. Hester and R.B. Girling (Royal Soc. of CHem.) 403 (1991)

[8] T. Shimanguchi, M. Tsuboind Y.Kyogobu, Adv. Chem. Phys. (Inter Science, New York) 7(P), 435 (1964).

[9] S. R. Karumuri, J. Choudhury, N. K Sarkar, B. Gogoi and R. Bhattacharjee Indian J. Phys. 84 (6), 647-652 (2010).

[10] R. John Dyer, “ Applications of absorption Spectroscopy of Organic Compounds,”( Prinecton Hall, N.J. U.S.A.) (1965).

[11] Vir Singh, Seema, Subhash Chand B.S. Yadav, Oriental J. Chem, 12(1996) 295.

[12] W. West, "Chemical Applications of Spectroscopy," Inter Science Publishing Co., New York, (1965).

[13] S. Gunasekaran \& E. Sailatha, Indian J. Pure \& Appl. Phys., 46 (2008) 315.

[14] K.C. Medhi, Spectrochim. Acta A, 38,(1982) 717. 